\title{
Understanding the Inflation Targeting Debate
}

\author{
James B. Bullard
}

$\mathrm{T}$ he nomination of Ben Bernanke to be Chairman of the Federal Reserve Board has rekindled a smoldering debate in U.S. monetary policy circles-namely, whether the Federal Reserve should join the ranks of the world's inflation targeting central banks. "Inflation targeting" is a sometimes nebulous phrase used to describe a monetary policy style which, at its heart, has the central bank setting an explicit, long-run, numeric target for inflation. Beginning in the 1990s, several countries in the world, perhaps most prominently the United Kingdom, formally began inflation targeting. Bernanke is on the record favoring inflation targeting, while outgoing Chairman Alan Greenspan has been opposed.

One particularly relevant summary of this debate occurred at the conference "Inflation Targeting: Prospects and Problems," held at the Federal Reserve Bank of St. Louis in October 2003. ${ }^{1}$ At that conference, Bernanke, then a Fed Governor, participated in a panel discussion with Fed Governor Donald Kohn and European Central Bank (ECB) Executive Board member Otmar Issing. Governor Kohn, like Chairman Greenspan, has generally been opposed to inflation targeting. The ECB, the central bank most like the Fed in size and influence, has wrestled with inflation targeting issues since its inception in 1998. Thus, the panel provided an opportunity to debate the pros and cons of inflation targeting. What were the main arguments?

In his discussion, Bernanke stated that he felt there was an optimal, long-run inflation rate (OLIR) "that achieves the best average economic performance over time with respect to both the inflation and output objectives" [p. 166]. There would be no drawback, in Bernanke's view, to announcing an explicit target in the neighborhood of 2 percent, provided the FOMC makes no particular commitment to a timetable for reaching the OLIR. This last proviso would make sure that there were "no unwanted constraints on short-run monetary policy" [p. 167]. In suggesting a numerical target near 2 percent, Bernanke emphasized that very low levels of inflation are generally preferred, but not so low that the FOMC would face an unacceptably high risk of encountering the zero lower bound on nominal interest rates, as has occurred in Japan over the past decade.

The ECB experience is perhaps only cold comfort for the United States. Issing stressed that euro-zone monetary policy has been implemented only since 1999 and that many of the issues surrounding the introduction of the euro are special. Still, the

ECB Governing Council did successfully introduce the new currency after adopting price stability as a main objective. The Council stated that it would strive to maintain a euro-zone inflation rate "below but close to 2 percent over the medium term" [p. 175]. Issing, like Bernanke, felt that 2 percent was reasonable in part because "a sufficient safety margin against the risk of deflation" [p. 175] was needed. Issing also emphasized that inflation targeting approaches often call for the central bank to adjust its nominal interest rate target in response to an inflation forecast. He warned that actual forecasts may not summarize all factors important for price stability; in addition, the forecasting model may be misspecified, reflecting economists' uncertainty about the true nature of the macroeconomy. Issing labeled these concerns "practical pitfalls" of inflation targeting [p. 172].

Kohn argued that adoption of inflation targeting might actually lead to worse economic performance relative to what has been achieved in the past two decades, stating that "the U.S. economy has benefited from the flexibility that the Federal Reserve has derived by eschewing a formal inflation target" [p. 180]. He questioned whether there was evidence that inflation targeting countries have actually witnessed benefits relative to non-inflation targeting countries. Like Issing, Kohn emphasized that there are many factors in actual policymaking that inflation targeting approaches may be ill-suited to handle. He concluded by stating that "those who propose changes from a good system have a high burden of proof. The marginal benefits [of changes] are not likely to be high [and may have] unintended consequences" [p. 183].

The panel discussion makes it clear that Bernanke was thinking mostly in terms of the merits of setting an explicit, numerical inflation target. He allowed the proviso that the Fed should make no commitment about a timetable to return inflation to this target, providing flexibility to policymakers to respond to special factors that may be influencing the economy. Issing and Kohn expressed little or only moderate concern with an explicit inflation target, but had more serious reservations about unwittingly placing constraints on policymakers, limiting their ability to manage the risks that naturally arise day to day. Thus, the core of the debate concerns whether adoption of inflation targeting would place important short-run constraints on policymakers and, if so, whether that is a good idea or not.

${ }^{1}$ The conference proceedings, including the panel discussion, are published in the Federal Reserve Bank of St. Louis Review, July/August 2004, 86(4). 